\title{
Influence of Multiple-Support Excitation on Seismic Response of Reinforced Concrete Arch Bridges
}

\author{
Marta Savor Novak*(D), Damir Lazarevic, Josip Atalic and Mario Uros $\mathbb{D}$ \\ Department of Engineering Mechanics, Faculty of Civil Engineering, University of Zagreb, 10000 Zagreb, \\ Croatia; damir@grad.hr (D.L.); atalic@grad.hr (J.A.); uros@grad.hr (M.U.) \\ * Correspondence: msavor@grad.hr; Tel.: +385-91-5053-243
}

Received: 1 November 2019; Accepted: 16 December 2019; Published: 18 December 2019

Featured Application: Suggested application includes the seismic analysis of long-span reinforced concrete deck arch bridges. Furthermore, results of this study may be acknowledged in drafting design guidelines and standards for earthquake resistance of bridges, as most of the studies which were the basis for standard rules considered only beam bridges.

\begin{abstract}
Although post-earthquake observations identified spatial variation of ground motion (i.e., multiple-support excitation) as a frequent cause of the unfavorable response of long-span bridges, this phenomenon is often not taken into account in seismic design to simplify the calculation procedure. This study investigates the influence of multiple-support excitation accounting for coherency loss and wave-passage effects on the seismic response of reinforced concrete deck arch bridges of long spans founded on rock sites. Parametric numerical study was conducted using the time-history method, the response spectrum method, and a simplified procedure according to the European seismic standards. Results showed that multiple-support excitation had a detrimental influence on response of almost all analyzed bridges regardless of considered arch span. Both considered spatial variation effects, acting separately or simultaneously, proved to be very important, with their relative significance depending on the response values and arch locations analyzed and seismic records used. Therefore, it is suggested that all spatially variable ground-motion effects are taken into account in seismic analysis of similar bridges.
\end{abstract}

Keywords: seismic analysis; multiple-support excitation; spatial variability; large-span reinforced concrete deck arch bridges; time-history method; generation of ground motion time histories

\section{Introduction}

Improvement of seismic design methods always follows new observations and analyses of damage and collapse due to major earthquakes. Conducted studies identified spatial variation of ground motion as a frequent cause of unfavorable response of long-span bridges, e.g., [1,2], but this phenomenon is usually not taken into account in seismic design to simplify the calculation procedure. Since length and spans of larger bridges are comparable to the seismic wavelength, it is obvious that all bridge supports cannot be excited simultaneously. Additional differences in the seismic input to different supports arise from changes in the frequency content and amplitude of the seismic waves propagating from the base rock to the ground surface. Simple examples of multiple-support excitations include the unseating of the superstructure due to differential displacements of its supports [2-4].

The pioneering studies of the phenomenon of ground motion spatial variation occurred in the 1960s [5], while significant improvements in the understanding of the phenomenon may be attributed to data recorded in strong-motion arrays such as SMART-1 (Strong Motion Array in Taiwan-Phase 1) [6], El Centro Differential Array, Thessaloniki in Greece, Pinyon Flat in the USA, among others $[7,8]$. 
The main causes of spatial variability in ground motions are attributed to coherency loss (loss of coherency of seismic waves due to reflections and refractions of waves in the heterogeneous medium of the ground and due to superposition of waves arriving from a seismic source), wave-passage effect (time delay in arrival of seismic waves to different supports of the structure), attenuation effects (decay of amplitudes and energy of seismic wave propagating through the ground) and local site conditions (different geological conditions at different supports influence frequency content and amplitudes of seismic waves) [9], schematically depicted in Figure 1 . The interested reader may refer to $[7,10,11]$ for a comprehensive overview of the subject.

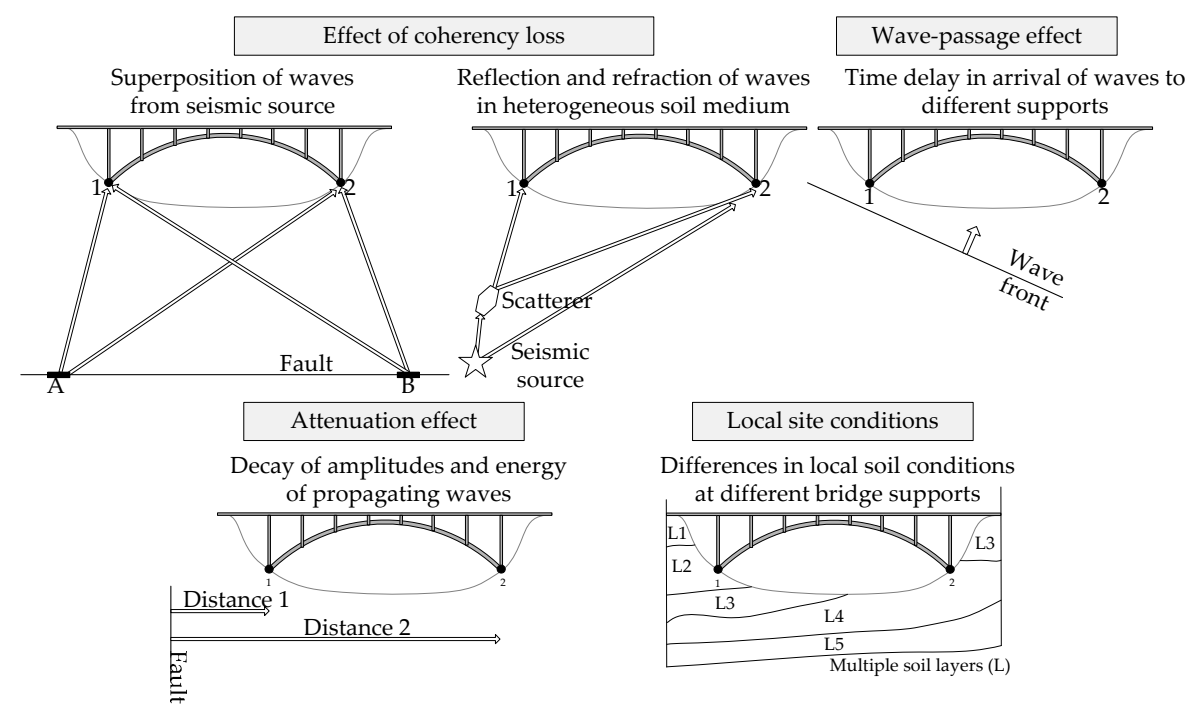

Figure 1. Principal forms of spatial variability of ground motion [12].

In general, random vibration methods, response spectrum methods and deterministic methods are used in the study of the multiple-support excitation effect in engineering applications. Although, numerous studies in which response of bridges to multiple-support excitation was analyzed using different methods may be found in literature (e.g., [2,13-22]), very little research has been devoted to arch bridges. Some detailed studies dealt with arch structures in general (e.g., [23-25]), while studies of arch bridges mostly considered steel bridges [26-28]. The most important conclusions from some of those studies will be summarized below. The results of the stochastic response of incompressible circular arches to multiple-support excitation presented in [23] showed that neglecting multiple-support excitation effect can underestimate, but also overestimate the response, depending on the properties of the arches, response quantities and the seismic excitation. The author concluded that wave-passage effect was more detrimental than the loss of coherence. However, Harichandran et al. [26] studied the responses of two-deck steel arch bridges of large span and showed that the coherency loss is also very important for response in addition to wave-passage effect. Authors concluded that uniform excitation is in general unacceptable for considered bridges. In the research [28] in which deck steel arch bridges were analyzed, it was concluded that the response to the multiple-support excitation was less detrimental than to the uniform one in the vertical and transverse directions, whereas in the longitudinal direction the multiple-support excitation significantly affects the response and should not be neglected.

Very limited investigations of concrete arch bridges found in literature are those in [29-33]. The seismic response of an existing reinforced concrete arch bridge of $150 \mathrm{~m}$ span to uniform and multiple-support excitation was investigated in [29]. The authors concluded that the multiple-support excitation significantly increases the longitudinal force in the arch, even exceeding its load-bearing capacity. The similar conclusion was reached by authors of [30] in which the response of several smaller-span reinforced concrete arch bridges was investigated and in [33] where authors considered only the wave-passage effect on the response of a reinforced concrete arch bridge of long span. It may 
be observed that no systematic study of the response of reinforced concrete arch bridges of large spans to multiple-support excitation may be found in literature.

It is common knowledge that the response to multiple-support excitation differs from uniformly excited response. Due to relative displacements of the supports, a quasi-static component of the response is induced, while dynamic component of the response also changes because different eigen-modes are excited to modes excited by uniform excitation. For instance, in symmetrical arch bridges, uniform excitation in the longitudinal direction of the bridge excites only the antisymmetric vibration modes, while in the case of multiple-support excitation, both symmetric and antisymmetric modes are activated (Figure 2), including the higher modes, which should not be neglected in the analysis. It is interesting to mention studies presented in [19,34], despite the fact that a cable-stayed bridge (not an arch one) was studied. On the basis of monitoring a real structure (free-field and on-structure recordings) it was revealed that the asynchronous excitation of a bridge excited higher modes of vibration while suppressing the oscillation in its fundamental frequency.

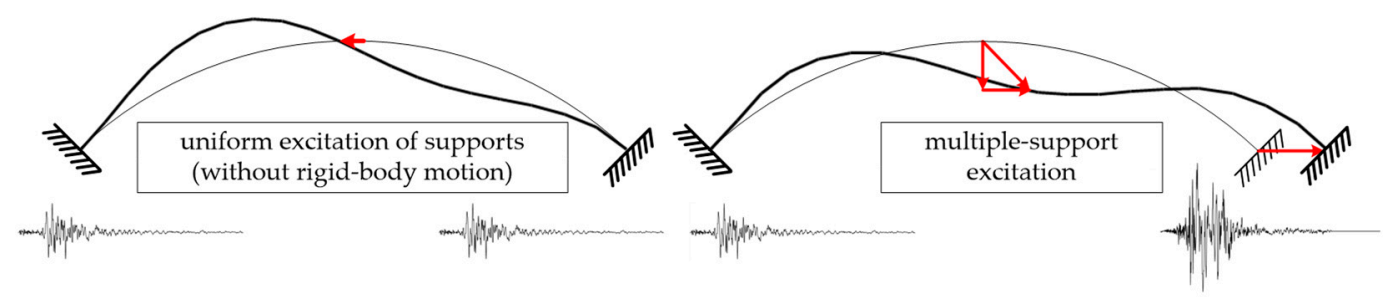

Figure 2. Relative arch displacements due to the uniform and multiple-support excitation [10].

To summarize, in the research community there is still no consensus whether the multiple-support excitation phenomenon is favorable or detrimental for seismic response of structures, because it depends on many parameters, including the excitation features, soil characteristics and dynamic characteristics of excited structure. Therefore, the objective of this paper is to study its effect on seismic response of long-span reinforced concrete deck arch bridges, the structural system which has not yet been investigated in detail regarding this effect. This study contributes to better understanding of seismic behavior of these structures and it aims to give guidelines whether the multiple-support excitation should be considered for seismic analysis of bridges of similar structural systems and spans. Analyses were conducted using state-of-the art methodologies and tools on bridge prototype numerical models of different spans. The methodology for conducted research is described in detail in [12], but for the legibility and clarity of the paper, the most important features will be repeated herein. Detailed analysis results presented in this paper showed that multiple-support excitation had an unfavorable effect on the seismic behavior of analyzed bridges. Hence, this phenomenon should be considered in the design of bridges of similar layouts.

\section{Prototype Bridges}

\subsection{Bridge Prototypes Description}

Numerical models represent bridges of layout, material properties and cross-sections dimensions that are verified for persistent design situations [35]. Analyzed bridges were of arch spans L $=100 \mathrm{~m}$, $200 \mathrm{~m}, 300 \mathrm{~m}$ and $400 \mathrm{~m}$ with the rise to span ratio of 0.2 (Figure 3) and shaped as catenary with constant springing to crown load ratio. Deck spans were between $28 \mathrm{~m}$ and $33.5 \mathrm{~m}$ for all bridges. Three different sets of bridge layouts were analyzed in order to investigate the influence of dynamic properties of the structural system on the seismic response to multiple-support excitation. In the first set, the connection between spandrel columns and the superstructure is hinged (provided by fixed bearings), the connection is fixed in the second set, while in the third one it is also monolithic but the arch is additionally stiffened (using large cross section) in order to analyze the influence of the arch stiffness on bridge response. It was assumed that superstructure is connected to abutments by longitudinally movable bearings. Bridges are founded on a good-quality rock (corresponding to 
ground type A according to Eurocode 8 [36]). It is important to mention that bridges with different site conditions were not studied and local site effect was not accounted for.

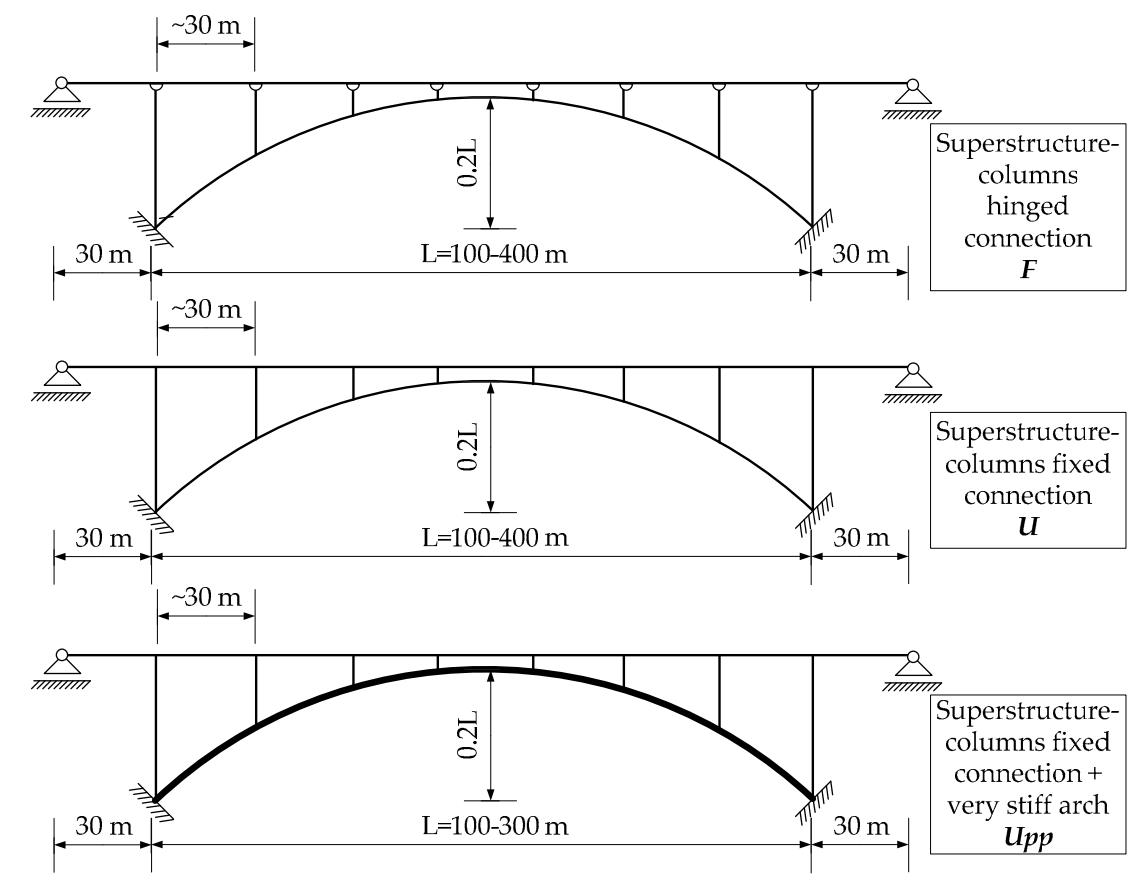

Figure 3. Layout of analyzed bridges.

Figure 4 presents cross sections of the bridge. The superstructure, spandrel columns, portal columns and arches are of cell-box type cross sections with constant dimensions given in Table 1 . The designed concrete grade for the arch and superstructure is C45/55 and C35/45 for the columns [37]. Diaphragms are placed inside the arch under spandrel columns. Their width is equal to the width of spandrel columns that they support. The arch is connected to arch abutments by a diaphragm.

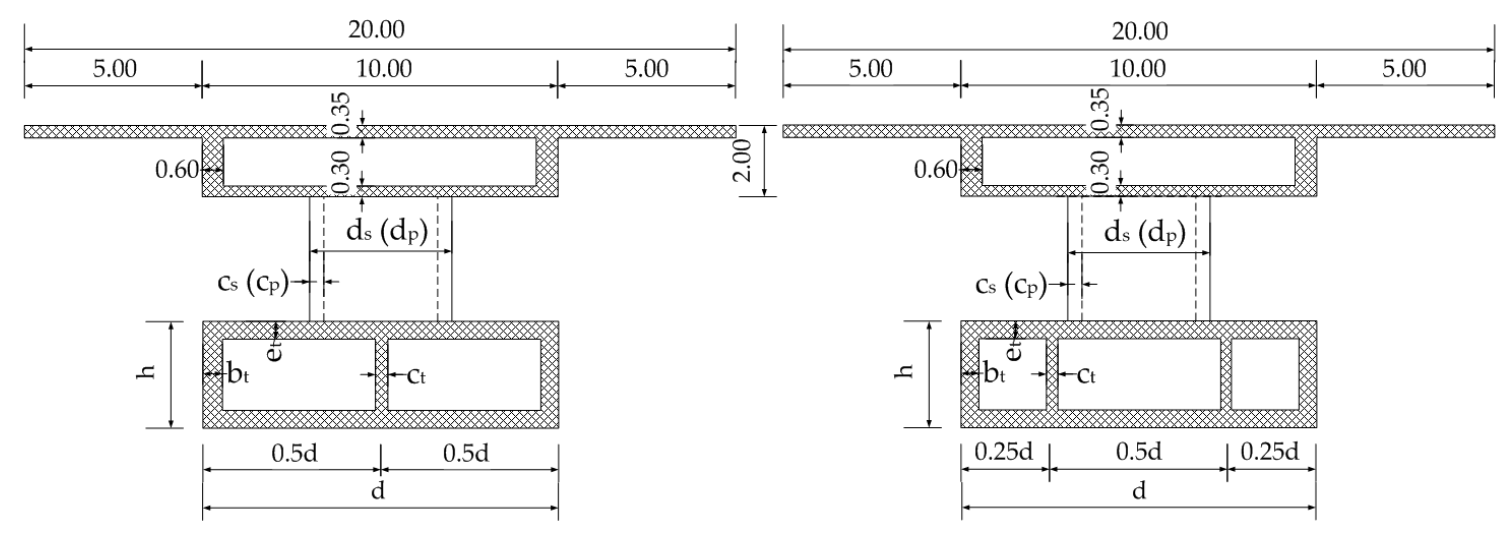

(a)

(b)

Figure 4. Cross sections of the bridges: (a) Spans L = 100 and $200 \mathrm{~m}$; (b) Spans L = 300 and $400 \mathrm{~m}$. 
Table 1. Cross-section dimensions of arches and columns.

\begin{tabular}{|c|c|c|c|c|c|c|c|c|}
\hline Span L [m] & $\begin{array}{c}\text { Arch Outer } \\
\text { Dimensions d } \\
\times \mathrm{h}[\mathrm{m}]\end{array}$ & $\begin{array}{c}\text { Arch Outer } \\
\text { Web Thickness } \\
b_{t}[\mathrm{~m}]\end{array}$ & $\begin{array}{c}\text { Arch inner Web } \\
\text { Thickness } c_{t} \\
{[\mathrm{~m}]}\end{array}$ & $\begin{array}{c}\text { Arch Chord } \\
\text { Thicknesse }_{t} \\
\text { [m] }\end{array}$ & $\begin{array}{c}\text { Column Outer } \\
\text { Dimensionsd } \\
\quad \times b_{\mathrm{s}}[\mathrm{m}]\end{array}$ & $\begin{array}{l}\text { Thickness of } \\
\text { the Column } \\
\text { Chords } c_{s}[\mathrm{~m}]\end{array}$ & $\begin{array}{c}\text { Portal Outer } \\
\text { Dimensionsd }_{p} \\
\quad \times b_{p}[\mathrm{~m}]\end{array}$ & $\begin{array}{c}\text { Portal Chords } \\
\text { Thickness } c_{p} \\
\text { [m] }\end{array}$ \\
\hline 100 & $10 \times 2$ & 0.30 & 0.30 & 0.45 & $3.0 \times 1.5$ & 0.30 & $4.0 \times 2.0$ & 0.50 \\
\hline 200 & $10 \times 3$ & 0.50 & 0.30 & 0.50 & $5.0 \times 2.5$ & 0.30 & $6.5 \times 3.5$ & 0.50 \\
\hline 300 & $11 \times 5$ & 0.50 & 0.50 & 0.50 & $5.0 \times 2.5$ & 0.30 & $6.5 \times 3.5$ & 0.50 \\
\hline 400 & $12 \times 7$ & 0.60 & 0.60 & 0.60 & $5.0 \times 2.5$ & 0.30 & $6.5 \times 3.5$ & 0.50 \\
\hline
\end{tabular}




\subsection{Numerical Modelling Strategies}

Two-dimensional beam finite-element models were created for all bridge prototypes, with precise geometry and appropriate spatial and time discretization of the problem, essential for calculation of high-frequency vibration modes [38].

Influence of geometric non-linearity was investigated in this research. This effect takes into account increase of stiffness for elements subjected to a tension force and reduction of stiffness for elements subjected to a compression force ("softening" of structural elements), such as the arch. In the first case, numerical models for dynamic analysis were determined in the classical way, not taking into account the change in the stiffness matrix due to dead loads action. In the second case, the analysis was performed using the stiffness matrix inherited from geometric non-linear staged construction design. The results from the two cases were compared (dynamical properties, internal forces and displacements for the vertical load and for one case of multiple-support excitation (MSE)) and the differences were less than $10 \%$. Hence, this effect was excluded in further analyses to MSE.

Material nonlinearity of the bridge cross sections was not accounted for, as it was assumed that all load-bearing bridge elements respond in the elastic range. Arch response is mostly non-ductile due to high thrust [39]. The energy loss in elastic range was simulated by Rayleigh damping wherein the damping of the first mode and the mode for which the modal participating mass ratio exceeds $90 \%$ is assumed with the value of $5 \%$. The Ritz vectors determined from inertia loads (mass for unit acceleration) along two directions were used instead of classic eigenvectors. This avoids the negative property of eigen-value problem where eigen-modes are generated independent of the load type, so many eigen-vectors contribute very little or nothing to total active mass of the structure. The latter means that they are orthogonal or almost orthogonal to inertia loads. Therefore, an approach to avoid this phenomenon in numerical models is the application of Ritz-vectors, determined from inertia forces acting on the structure. In other words, displacements from these loadings represent the starting vector for the iterative procedure for calculating appropriate Ritz vibration vectors. Fifty Ritz vectors were determined in all numerical models, to obtain static and dynamic modal load participating coefficients of almost $100 \%$ in translational directions. For comparison, more than double of classical eigen-vectors would have to be determined to obtain approximately the same values of static and dynamic modal load contributions. If the loads are proportional to mass of the structure, contribution coefficients are in accordance with the total contribution coefficient of modal masses. It should be noted, though, that for many Ritz vectors a very precise numerical model is mandatory, to minimize the discretization error in determining high oscillation modes (with many zero points), necessary for analysis of structures to MSE, to acceptable level. The algorithm for the generation of Ritz vectors may be found in [38].

As bridges are founded on rock, supports were modeled accordingly as springs of large stiffness. Abutments were not considered in numerical models.

Diaphragms placed inside the arch and those near abutments are not explicitly modelled, but their weight is taken into account. Additional dead load acting on the superstructure includes all bridge equipment and pavement layers.

All numerical models were created and analyzed in Sap2000 software [40], while the benchmark examples of the bridge of $100 \mathrm{~m}$ span were analyzed in Wolfram Mathematica [41] and Seismostruct [42]. One of the benchmark examples was presented in [12].

\section{Methodology}

\subsection{Model of Spatial Variability of Ground Motion}

The ground motion spatial variability is often probabilistically described using the space-time random field of ground motion, with data obtained from the series of dense instrument arrays. Thus, this model can be expressed through cross-power spectral density of the motions $S\left(\xi_{j k}, \omega\right)=S(\omega) \cdot \gamma_{j k}\left(\xi_{j k}, \omega\right)$ where $S(\omega)$ is the power spectral density function of the motions, $\xi_{j k}$ is the distance of supports $j$ and $k$, and $\gamma_{j k}\left(\xi_{j k}, \omega\right)$ is the complex coherency. The complex coherency $\gamma_{j k}\left(\xi_{j k}, \omega\right)$ 
for each frequency range contains the amplitude term representing coherency loss $\left|\gamma_{j k}\left(\xi_{j k}, \omega\right)\right|$ and the phase term $\theta_{j k}\left(\xi_{j k}, \omega\right)$ representing the wave-passage effect.

The coherency loss is usually described by means of the lagged coherency, which is the measure of linear statistical dependence between seismic motions. For the perfectly linearly dependent processes the value is one, while it is zero for the completely independent processes. It is expected that at short distances and at low frequencies the motions will be similar, while for large distances and at large frequencies the motions will become uncorrelated [8].

Most lagged coherency functions have been obtained empirically and semi-empirically using recorded data at strong motion arrays. Some of the empirical functions, developed mostly from the SMART-1 array, are those of Loh and Lin [43], Hao et al. [44], Abrahamson et al. [45], and Harichandran and Vanmarcke [46]. The functional form of semi-empirical models is analytically based, but parameters are evaluated from recorded data. Some of them are those proposed by Somerville et al. [47], Der Kiureghian [48] and Luco and Wong [49].

The selection of coherency model significantly affects the seismic response of structures subjected to multi-support excitation [7]. Hence, the recommendations for choosing the appropriate model from a large number available are necessary. The comprehensive discussion on this topic is presented in [8], where simulations of the motions from the two models very common in engineering applications, those of Harichandran and Vanmarcke [46] and of Luco and Wong [49], are compared. An important consideration in the selection of the coherency model is the site classification. The lagged coherency at rock sites has a flatter exponential decay than the lagged coherency at the softer soil sites. According to [7], coherency models at rock sites are limited. Abrahamson [50] proposed an empirical coherency model for rock sites based on recordings at the Pinyon Flat array. Luco and Wong coherency model with a range of slower exponential decays, compatible with the trend of recorded data, can also be used as representative for the coherency at rock sites. Therefore, in this study the loss of coherency was modelled using this function, given by the expression:

$$
\left|\gamma_{j k}\left(\xi_{j k}, \omega\right)\right|=e^{-\alpha^{2} \omega^{2} \xi_{j k}^{2}}
$$

in which parameter $\alpha$ controls the exponential drop of the coherency function with an increase of distance and frequency. Parameter $\alpha$ was taken with value of $2 \times 10^{-4}$, the lowest value of those proposed by Luco and Wong, to be appropriate for the rock site.

The wave-passage effect depends on the apparent velocity of the waves. According to Abrahamson [51], studies of motions recorded in several arrays showed that the apparent velocity of S-waves is typically in the range $2.0-3.5 \mathrm{~km} / \mathrm{s}$. Hence, the value of $2 \mathrm{~km} / \mathrm{s}$ was chosen in this study. It was assumed that seismic wave propagated from the left abutment as the reference station to the other bridge supports in the direction of the main bridge axis.

Although the expansion of Kanai-Tajimi spectra [52] developed by Clough and Penzien [53] is usually selected as the spectral density function, in this study the proposal by Kaul [54] was followed for generating time-histories in order to reach matching with target spectra in fewer iterations:

$$
S(\omega)=\frac{2 \zeta}{\pi \omega} \cdot R S A^{2}(\omega) \cdot \frac{1}{-2 \ln \left(-\frac{\pi}{\omega T} \ln p\right)}
$$

where RSA correspond to target spectra ordinates, $\zeta$ is the damping coefficient, $T$ is duration of the generated records and $p$ is probabilistic coefficient, usually $\geq 0.85$ [54].

In this study, the Eurocode 8 elastic pseudoacceleration spectrum of type 1 for ground type A [36] with peak ground acceleration of $0.2 \mathrm{~g}$ was chosen as the target response spectrum. Duration of the records was $20 \mathrm{~s}$ [15] and $p$ was taken with the value of 0.85 , in accordance with [54]. 


\subsection{Analysis Methods and Multiple-Support Analysis Cases}

As already mentioned in the Introduction, the methods used in this study are in accordance with [12], but the most important features will be summarized herein. Analysis methods include response spectrum method according to Der Kiureghian and Neuenhofer (using Multiple Support Response Spectrum (MSRS) fortran code) [55,56], time-history method using generated records and simplified procedure for consideration of spatially variable seismic excitation proposed in Eurocode 8 [57]. The fundamental information on these methods is presented in Figure 5, while the methods of generating records for time-history method will be briefly elaborated below.

\begin{tabular}{|l|}
\hline \multicolumn{1}{|c|}{ Multiple support response } \\
spectrum method (MSRS) [56] \\
\hline - Stochastic method which takes into \\
account the effect of correlation \\
between motion of supports and \\
natural modes of vibration of the \\
structure \\
- Limitation to linear structures with \\
classical damping \\
- Statistical response quantities \\
Input data: \\
- Geometry of supports \\
- Modal frequencies and damping \\
ratios \\
- Effective influence coefficients and \\
effective modal participating factors \\
for each response quantity of \\
interest \\
- The set of peak ground \\
displacements and displacement \\
response spectra \\
- Coherency model \\
- Direction of propagation of seismic \\
waves, duration of motion \\
\end{tabular}

Time-history method (TH)

- The most general procedure of dynamic response calculation

- Equations of motion are solved by time stepping methods

- Numerically demanding and time consuming

Input data

- Displacement time-histories for SVGM (from recorded or simulated motions)

Ground motions simulation

techniques in this study:

- Conditional simulation by Deodatis [58]

- Unconditional simulation by

Vanmarcke et al. [59]

- NYCDOT prescribed time-histories [61]

Figure 5. Analysis methods applied in this study.
Simplified method according to EC8 [57]

- SVGM estimated by pseudo-static effects of appropriate displacement sets imposed at foundations of the supports

Input data:

- Two sets of displacements on the relevant support foundations

- Design response spectrum corresponding to most severe ground type underneath the bridge supports

Combination of the most unfavorable dynamic response and the most unfavorable effects obtained by quasistatic calculations, using SRSS rule

\begin{tabular}{|c|c|c|c|c|}
\hline $\begin{array}{c}\text { Arch } \\
\text { span }[\mathrm{m}]\end{array}$ & $\begin{array}{c}d_{1}(\mathrm{~A}) \\
{[\mathrm{m}]} \\
\end{array}$ & $\begin{array}{c}d_{2}(\mathrm{~A}) \\
{[\mathrm{m}]}\end{array}$ & $\begin{array}{c}d_{1}(\mathrm{~B}) \\
{[\mathrm{m}]}\end{array}$ & $\begin{array}{c}d_{2}(\mathrm{~B}) \\
{[\mathrm{m}]}\end{array}$ \\
\hline 100 & 0 & $9.25 \times 10^{-3}$ & $-2.31 \times 10^{-3}$ & $+2.31 \times 10^{-3}$ \\
\hline 200 & 0 & $1.85 \times 10^{-2}$ & $-4.62 \times 10^{-3}$ & $+4.62 \times 10^{-3}$ \\
\hline 300 & 0 & $2.78 \times 10^{-2}$ & $-6.94 \times 10^{-3}$ & $+6.94 \times 10^{-3}$ \\
\hline 400 & 0 & $3.70 \times 10^{-2}$ & $-9.25 \times 10^{-3}$ & $+9.25 \times 10^{-3}$ \\
\hline
\end{tabular}

Ground-motion records needed for time-history method were generated using two procedures. In the first one, conditional simulation using spectral representation method proposed by Deodatis [58] was applied, but with his extension to adjust the records to be compatible with the target spectra. In this study, the procedure was coded in Wolfram Mathematica according to the scheme presented in Figure 6.

The second procedure is unconditional simulation proposed by Vanmarcke et al. [59] in which a recorded ground motion is applied for generation of ground motions at other supports based on a spatial variability model. Basic input consisted of location of the supports, the spectral density function (SDF), the frequency-dependent spatial correlation function and the known ground motion at support. The procedure was performed in the program SIMQKE-II [60].

In addition to records generated by conditional and unconditional method, time-histories provided by seismic guidelines of New York City Department of Transportation (NYCDOT) were also applied [61]. These are readily available spatially-variable time histories sets for 1000-year, 1500-year and 2500-year earthquake return periods. Each one of these three sets incorporates the effects of spatial variation along 21 hypothetical piers on very hard rock spaced at $100 \mathrm{~m}$ and extended over a straight line having a total length of $2 \mathrm{~km}$. The formulation used for generation is according to Abrahamson [50]. NYCDOT motions were used for checks as they are not compatible with Eurocode spectrum. In total, 13 ground motion sets were generated using the unconditional simulation, 7 using conditional simulation and 3 sets of prescribed motions were taken from the NYCDOT standards. 


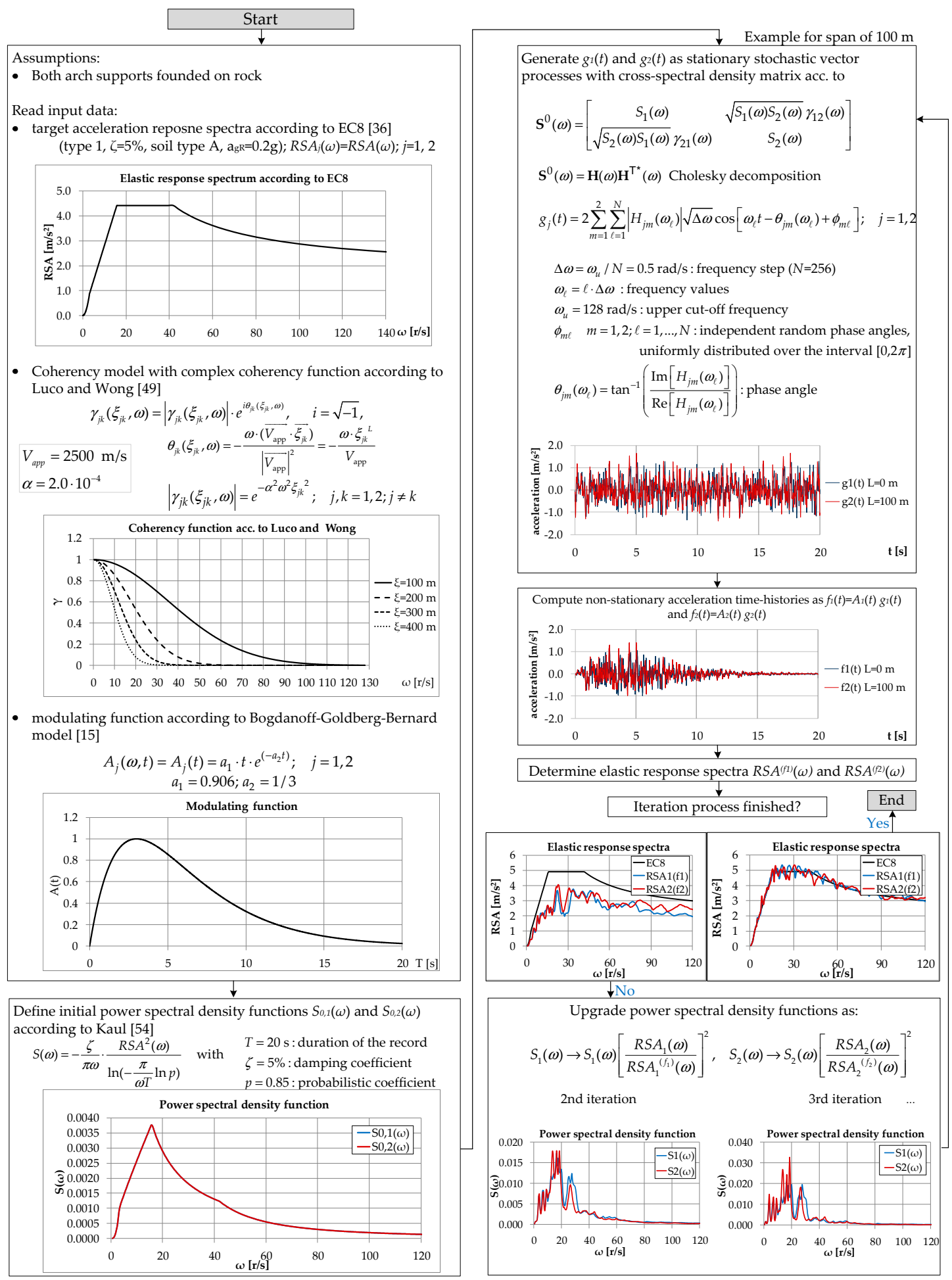

Figure 6. Scheme of iteration procedure for generating seismic motions compatible with target response spectrum.

Elastic response spectra of recorded motions at the left abutment (for conditional simulation method) and spectra of generated motions using unconditional method and of prescribed motions by NYCDOT are presented in the left part of Figure 7. On the right side of the same figure, one example set of displacement records at bridge supports is shown. 


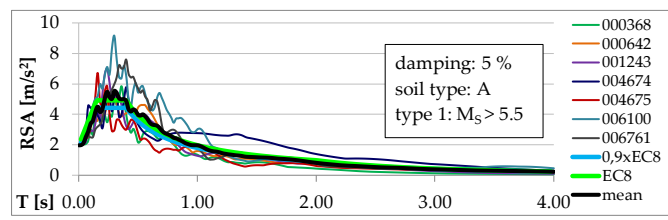

(a)

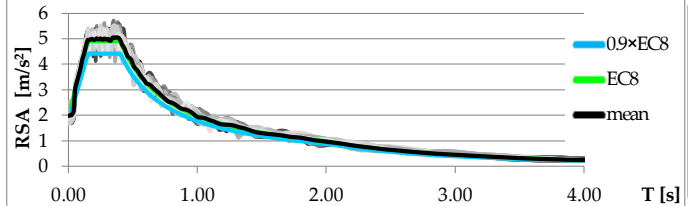

(c)

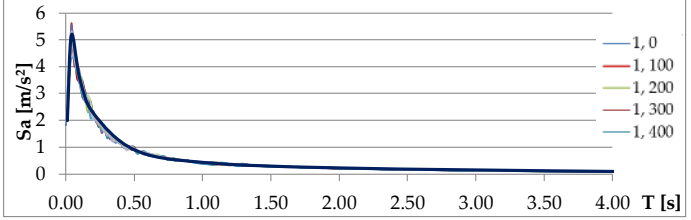

(e)

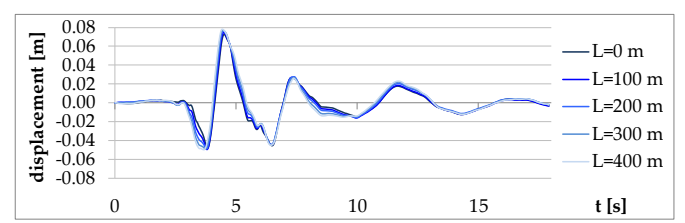

(b)

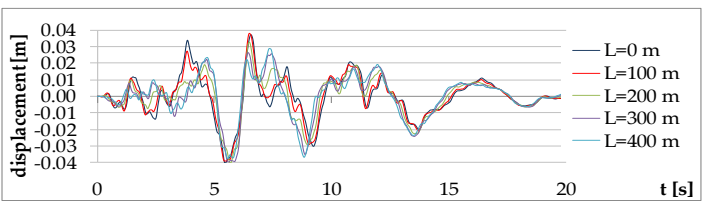

(d)

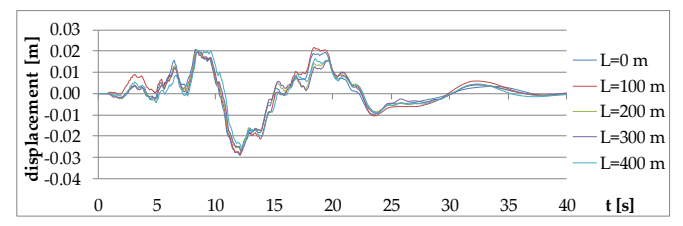

(f)

Figure 7. Elastic response spectra (ERS) and displacement time-histories (DTH): (a) ERS of recorded motions at $L=0 \mathrm{~m}$ for conditional method; (b) DTH of the record 004674; (c) ERS of all generated motions using unconditional method; (d) DTH of one set of motions; (e) ERS of one set of motions prescribed by New York City Department of Transportation (NYCDOT); (f) DTH of one set of motions prescribed by NYCDOT.

It is important to point out that, generally, the response of structures to MSE cannot be analyzed using the recorded accelerograms only, as a large number of simultaneously recorded time-histories at different distances, in different soils, of different magnitudes, etc., should be available. As such seismic database does not exist, a procedure for generation of records must be applied. For example, Eurocode 8 [57] in its informative annex D related to MSE does not even mention the use of recorded motions in time-history analysis, but only the generated ones. Their number should be such as to yield stable estimates of the mean of the maximum responses of interest. Therefore, in this study the analysis was made with the 20 generated motions, excluding the NYCDOT ones.

Furthermore, in the part of the standard not directly related to MSE, where the time-history representation is discussed, it is suggested that the appropriate modified/simulated records are used when the recorded ones with location-compatible characteristics are not available. In every case, the average response spectra of the individual spectra of the used time-histories should be not lower than 1.3 times the $5 \%$ damped elastic response spectrum in the period range between $0.2 \mathrm{~T}_{1}$ and $1.5 \mathrm{~T}_{1}$, where $\mathrm{T}_{1}$ denotes the fundamental period of the structure. In general, when a three-dimensional analysis is being carried out, the components of each pair of time-histories should be applied simultaneously.

The Hilber-Hughes-Taylor direct integration method with $\alpha=0$ (abbreviated to HHT $\alpha$ ) was applied for numerical implementation of the time-history procedure. It is important to mention that very short time steps were used, because of the application of displacement ground motion records (versus traditionally used acceleration records) [38].

After verification of numerical models, the following seismic cases were analyzed:

- $\quad$ Case $1(\mathrm{U})$ : uniform ground excitation;

- $\quad$ Case 2 (WP): multiple-support excitation with time delay of the motions (wave-passage effect on perfectly coherent seismic waves);

- $\quad$ Case 3 (C): multiple-support excitation with the coherency loss (it is assumed that the velocity is approaching infinity);

- $\quad$ Case 4 (WPC): multiple-support excitation with WP and C. 


\section{Results}

\subsection{Dynamic Analysis}

In the following table (Table 2) the first 10 Ritz vectors and corresponding natural periods are presented. The first mode shape is antisymmetric for all analyzed bridges, with modal mass participation ratios in the longitudinal direction ranging from 50-70\% for arches of $100 \mathrm{~m} \mathrm{span,} \mathrm{35-38 \%}$ for $200 \mathrm{~m}$ spans, 33-35\% for $300 \mathrm{~m}$ spans and 32\% for $400 \mathrm{~m}$ spans. Second mode shape is symmetric for all analyzed bridges except for the bridge F100. The first two mode shapes of bridges with static system $F$ are presented in Figure 8.

Table 2. Periods corresponding to first 10 Ritz vectors of all analyzed bridges [s].

\begin{tabular}{cccccccccccc}
\hline \multirow{2}{*}{ Ritz v. } & \multicolumn{10}{c}{ Period [s] } \\
\cline { 2 - 12 } & F100 & U100 & Upp100 & F200 & U200 & Upp200 & F300 & U300 & Upp300 & F400 & U400 \\
\hline 1 & 0.768 & 0.645 & 0.344 & 1.596 & 1.322 & 0.705 & 2.547 & 2.226 & 1.560 & 2.959 & 2.726 \\
2 & 0.464 & 0.352 & 0.255 & 0.895 & 0.731 & 0.443 & 1.398 & 1.221 & 0.880 & 1.628 & 1.497 \\
3 & 0.424 & 0.318 & 0.246 & 0.485 & 0.403 & 0.273 & 0.746 & 0.657 & 0.476 & 0.878 & 0.801 \\
4 & 0.301 & 0.255 & 0.215 & 0.436 & 0.381 & 0.239 & 0.611 & 0.563 & 0.453 & 0.728 & 0.698 \\
5 & 0.281 & 0.224 & 0.190 & 0.433 & 0.275 & 0.222 & 0.540 & 0.419 & 0.339 & 0.715 & 0.550 \\
6 & 0.281 & 0.205 & 0.189 & 0.323 & 0.268 & 0.219 & 0.475 & 0.371 & 0.321 & 0.659 & 0.539 \\
7 & 0.254 & 0.190 & 0.140 & 0.282 & 0.222 & 0.195 & 0.387 & 0.334 & 0.293 & 0.613 & 0.503 \\
8 & 0.236 & 0.182 & 0.123 & 0.281 & 0.215 & 0.171 & 0.369 & 0.318 & 0.291 & 0.551 & 0.451 \\
9 & 0.177 & 0.145 & 0.105 & 0.260 & 0.203 & 0.162 & 0.355 & 0.283 & 0.230 & 0.444 & 0.377 \\
10 & 0.137 & 0.113 & 0.079 & 0.231 & 0.173 & 0.161 & 0.328 & 0.253 & 0.223 & 0.426 & 0.335 \\
\hline
\end{tabular}

$\mathrm{T}_{1}$

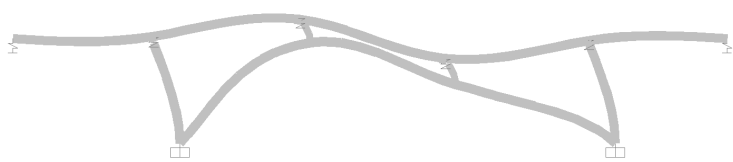

(a)

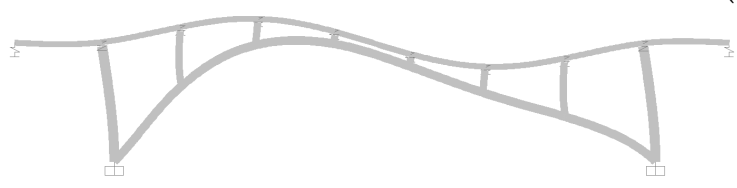

(b)

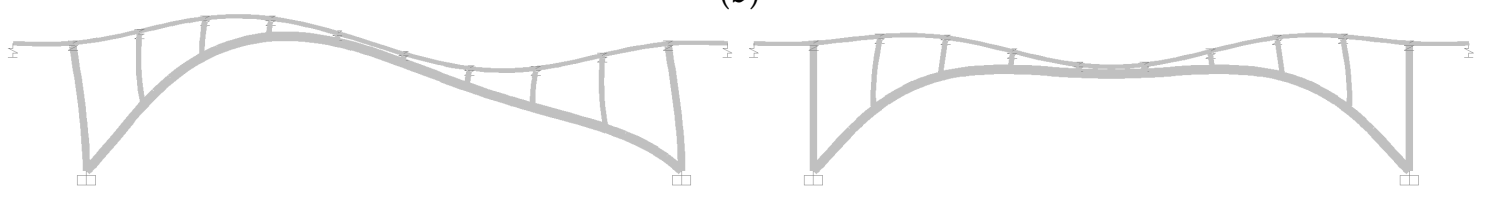

(c)

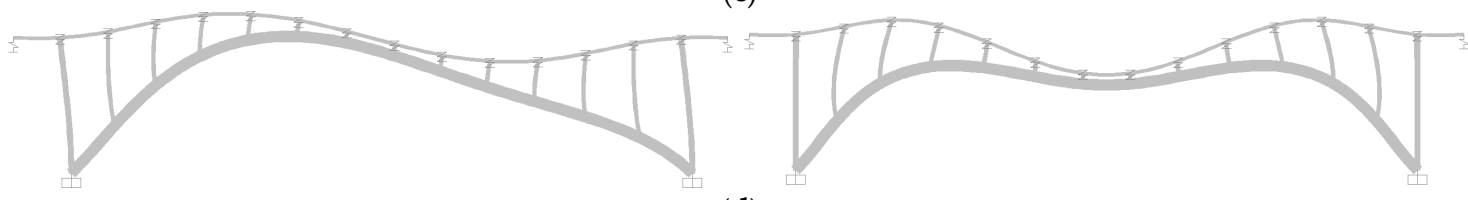

(d)

Figure 8. First two modes of vibration for bridges: (a) F100; (b) F200; (c) F300; (d) F400.

Elastic response spectrum from Eurocode 8 is presented in Figure 9, together with histogram of modal mass participation ratios larger than $5 \%$ for all analyzed bridges. As the earthquake records were generated to conform to the prescribed spectrum, it is interesting to determine where are the modes with large contribution of mass located in relation to the seismic load. It should be pointed out that the spectrum values are given in units $\left[\mathrm{m} / \mathrm{s}^{2}\right]$ which are shown on the left vertical axis, while the 
modal mass participation ratios are in [\%], shown on the right vertical axis. The different shades of colors have been used in histograms (blue for the modal mass participation ratios of $100 \mathrm{~m}$ span bridges, green for the $200 \mathrm{~m}$ span bridges, red/pink for the $300 \mathrm{~m}$ span bridges and orange for the $400 \mathrm{~m}$ span bridges).

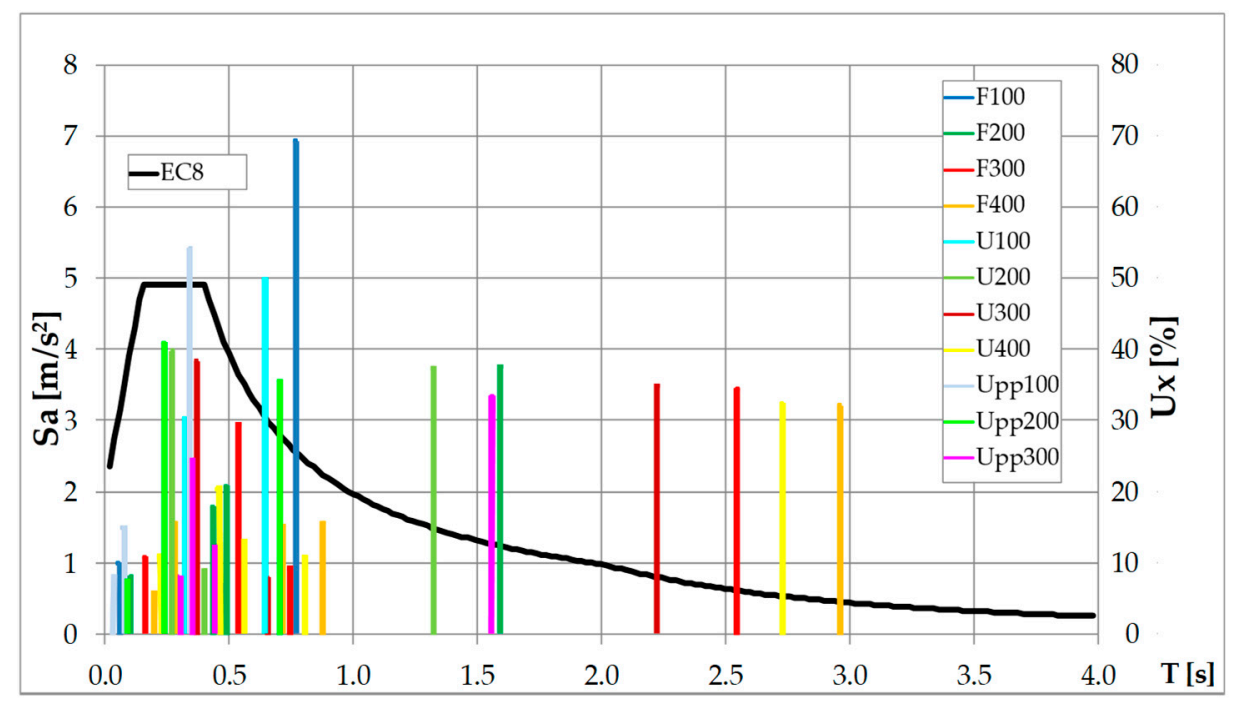

Figure 9. Elastic response spectra EC8 with modal mass participating ratios for all analyzed bridges.

\subsection{Seismic Analysis Accounting for Multiple-Support Excitation Effects}

Results are presented for the arch as the main load-bearing element. Arch sections in which axial force $(N)$, bending moment $(M)$, shear force $(T)$ and displacements $\left(u_{x}\right.$ and $\left.u_{z}\right)$ were analyzed include arch springings (p), quarter span (f) and arch crown (c).

Firstly, the results of seismic analysis using the time-history method will be presented. The ratio of absolute values of peak response for the multiple-support and uniform excitations was determined for each analyzed arch section and for each set of time-histories (20 in total, without NYCDOT motions) according to the expression:

$$
\rho_{1}=\frac{\text { peak response to the multi }- \text { support excitation }(\mathrm{C}, \mathrm{WP} \text { or WPC })}{\text { peak response to the uniform excitation }(\mathrm{U})}
$$

For ratios $\rho_{1}>1$, multiple-support excitation (MSE) has a detrimental effect on the seismic response in relation to the uniform excitation. The arithmetic mean of all the ratios for each set of time-histories and for each case of multiple-support excitation was calculated, and the standard deviation was $\sigma<1 / 3$ $\rho_{1}$ in all analyzed cases.

The average ratios $\rho_{1}$ for all analyzed cases of MSE are shown in Figures 10 and 11, for all analyzed bridges grouped by static system.

It may be observed that the most detrimental effect of MSE appears for the crown bending moment of the bridge U100 for the WPC case, with the ratio of 3.63. Regarding the displacements, the most unfavorable response occurs due to WPC case for the crown vertical displacement of the bridge Upp100, amounting to 1.86. Such a detrimental values occurring for MSE in the arch crown have been anticipated, because both symmetric and antisymmetric modes are excited. For uniform excitation symmetrical mode, shapes are not excited, so the crown of the symmetrical arch bridge does not undergo a vertical displacement (Figure 2) due to seismic action. Bending moments in the springings occurring for uniform excitation are acceptable for all bridges, except the very stiff ones (Upp) where the largest ratio amounts to 1.35 for the WPC case. However, the values at quarter span due to uniform excitation are unacceptable and the ratios are up to 1.45 for the WP case of the bridge Upp300. 
(a)

(b)

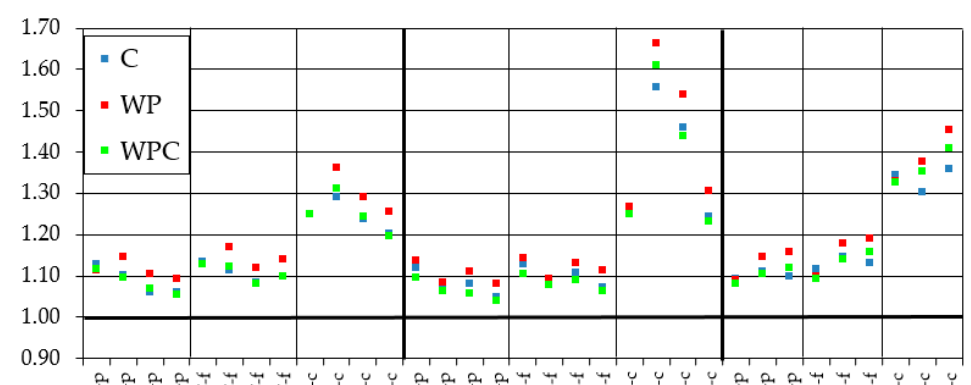

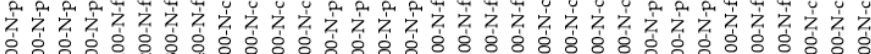

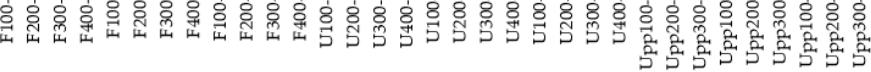

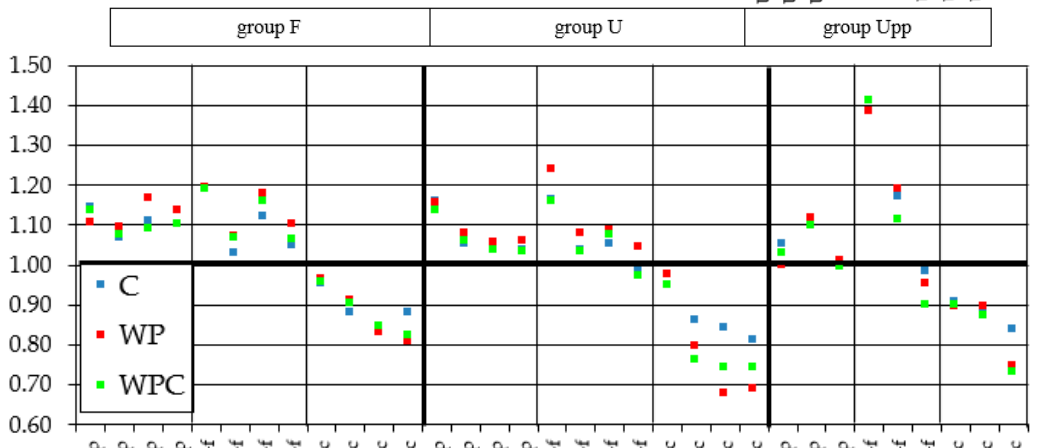

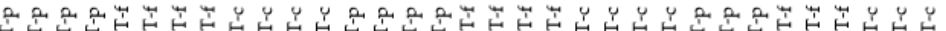

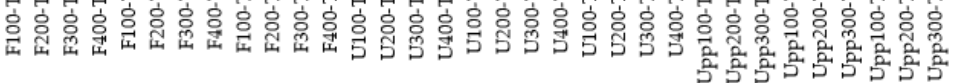

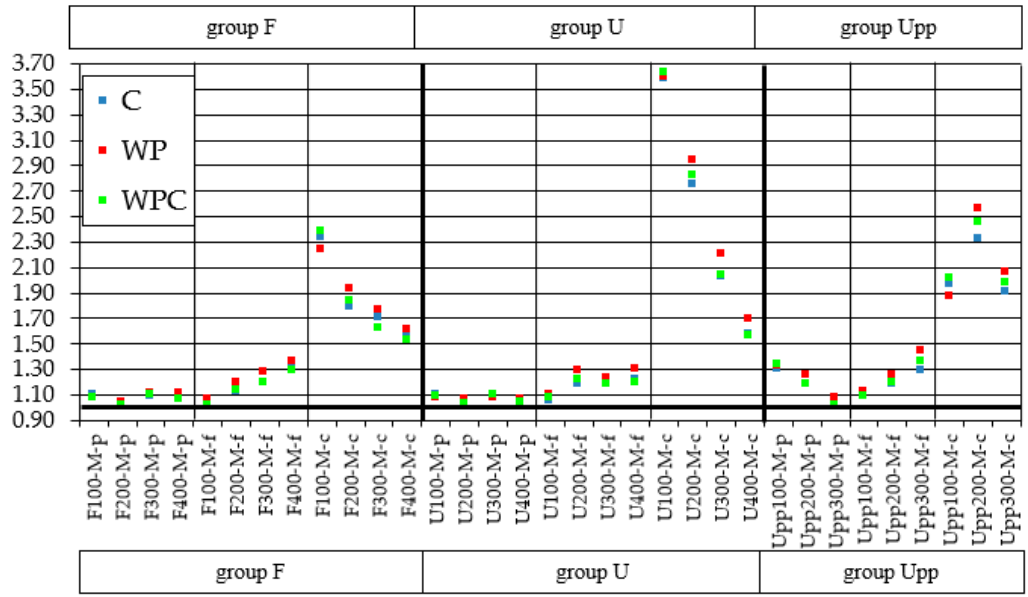

Figure 10. Ratios $\rho_{1}$ of all analyzed bridges grouped by static system: (a) axial forces; (b) shear forces; (c) bending moments.

Further unfavorable responses may be observed for axial forces in all analyzed sections of all the bridges, with the crown being the most critical one with ratios up to 1.68 of the bridge U200. It may be observed that in almost all analyzed cases the most unfavorable is the WP case. The unfavorable response of axial forces obtained is in accordance with the results presented in $[29,30,33]$.

Regarding the shear forces, the most detrimental response of MSE may be observed at the quarter span of the stiff bridges amounting to 1.42 for the WPC case of the bridge Upp100. For the shear force in the arch crown the uniform excitation is on the safe side.

All longitudinal displacements are in order of $\pm 10 \%$, so disregarding MSE is acceptable. 
(a)

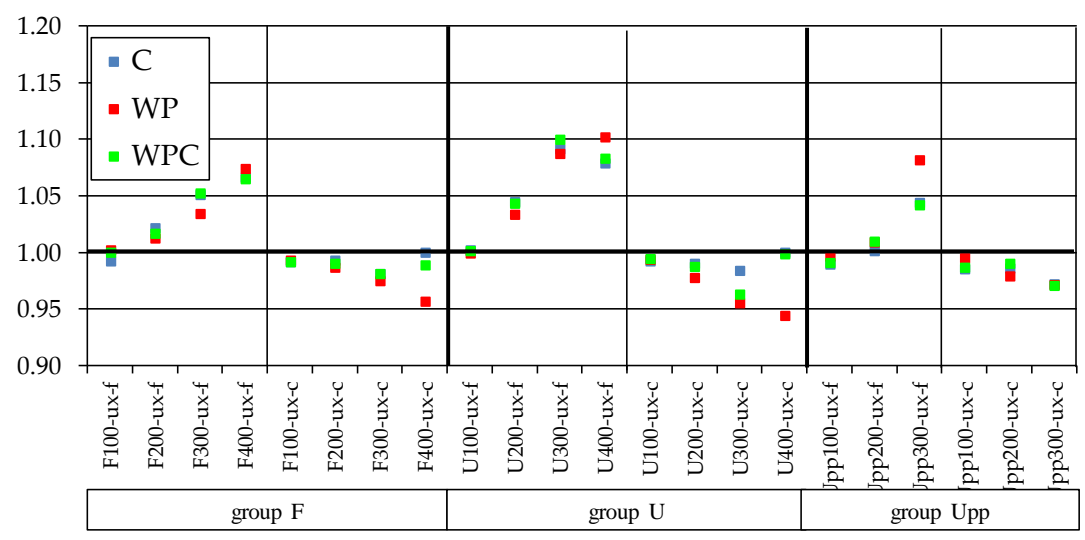

(b)

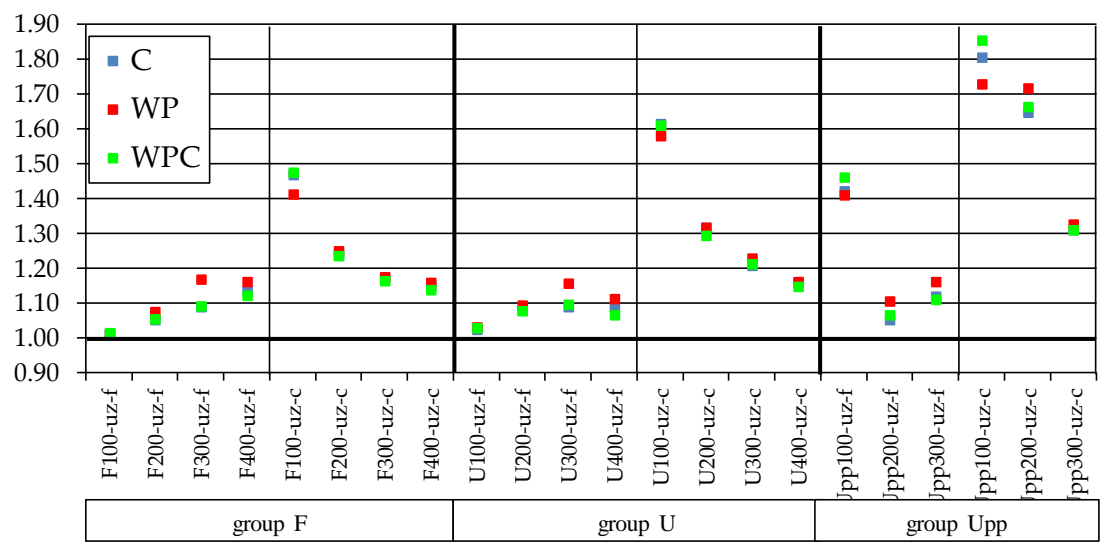

Figure 11. Ratios $\rho_{1}$ of all analyzed bridges grouped by static system: (a) horizontal displacements; (b) vertical displacements.

Following the results of time-histories, the ratio $\rho_{2}$ of the absolute values of peak response for the multiple-support cases calculated using different methods and the most detrimental case obtained by the time-history method using all generated records (UK) was determined for each analyzed arch section. Therefore, the average ratios $\rho_{2}$ are presented in Figures 12 and 13 in order to compare results of different analysis methods. Results of time-history method are given for records generated using different methods (denoted by $\mathrm{G}$ for unconditional simulation, $\mathrm{P}$ for conditional simulation, $\mathrm{N}$ for NYCDOT motions and UK for all generated motions excluding NYCDOT). The response spectrum method for multiple-support excitation is labelled as MSRS (analyses exclude the bridges of static system F). The cases of simplified method according to Eurocode 8 are labelled as EC8-SRSS for the case in which the combination of the most unfavorable dynamic response and the most unfavorable effects obtained by quasi-static analysis is calculated using the SRSS rule, while the approach in which this combination is obtained by summing absolute values of the dynamic and quasi-static response is labelled EC8-S. 


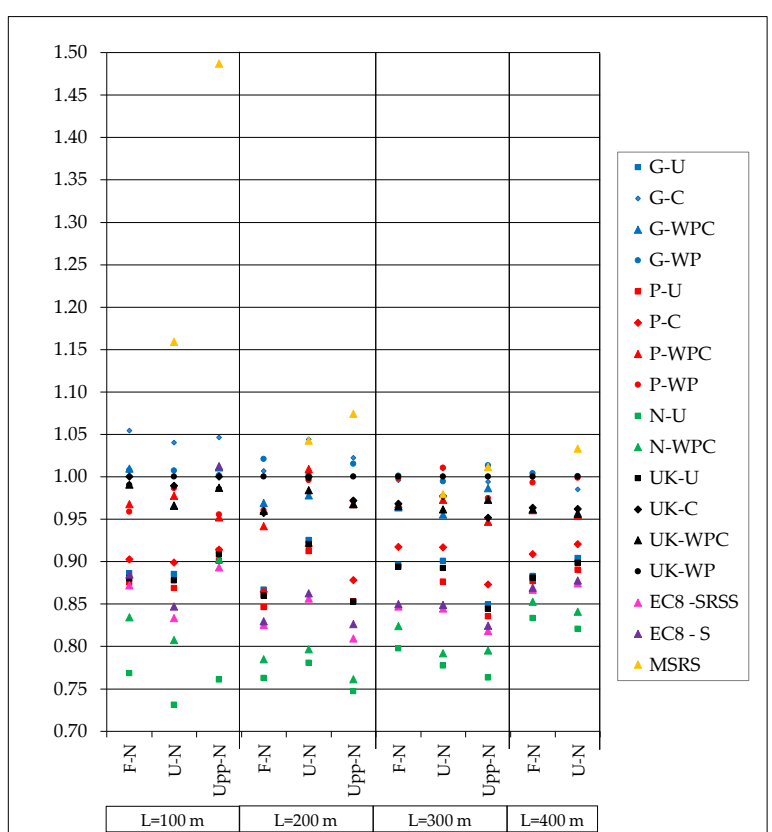

(a)

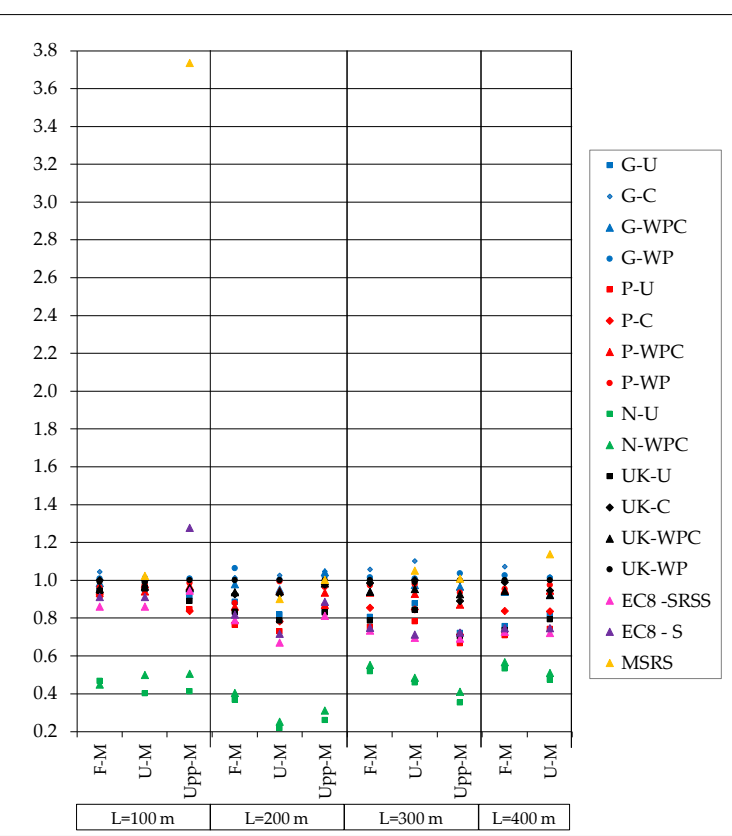

(b)

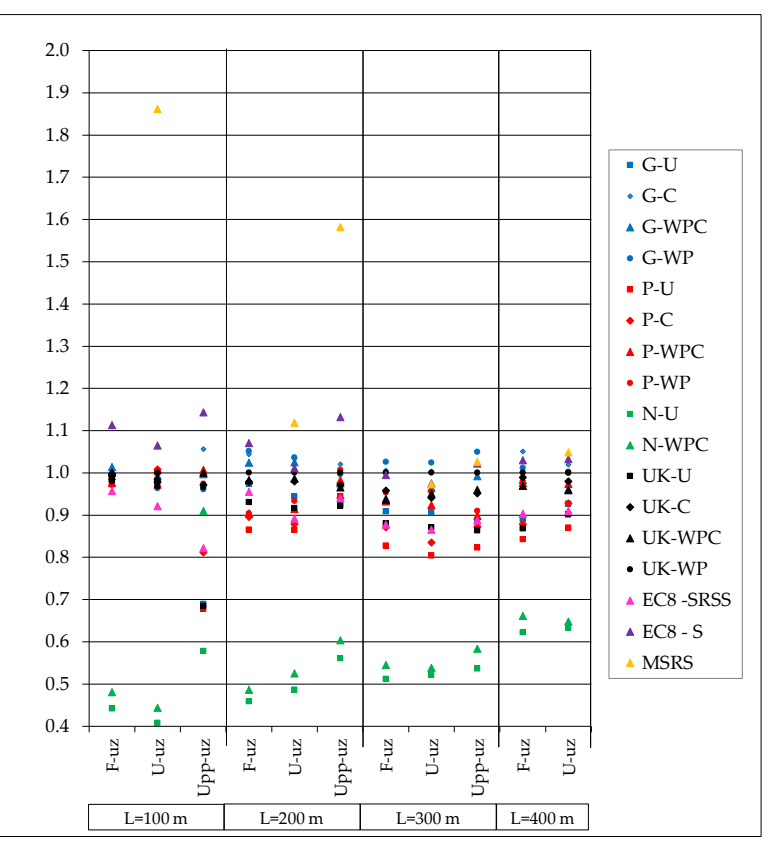

(c)

Figure 12. Ratios $\rho_{2}$ at arch quarter span for: (a) axial forces; (b) bending moments; (c) vertical displacements * * note: for clarity of the figure (c), the large $\rho_{2}$ of the bridge Upp100 amounting to 5.4 obtained using the MSRS method was disregarded. 


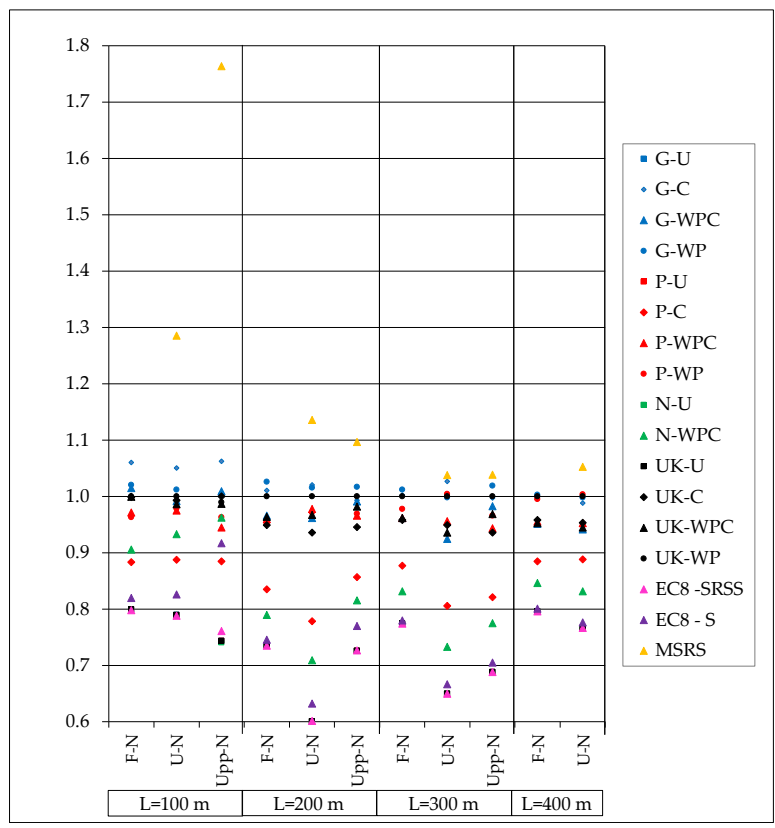

(a)

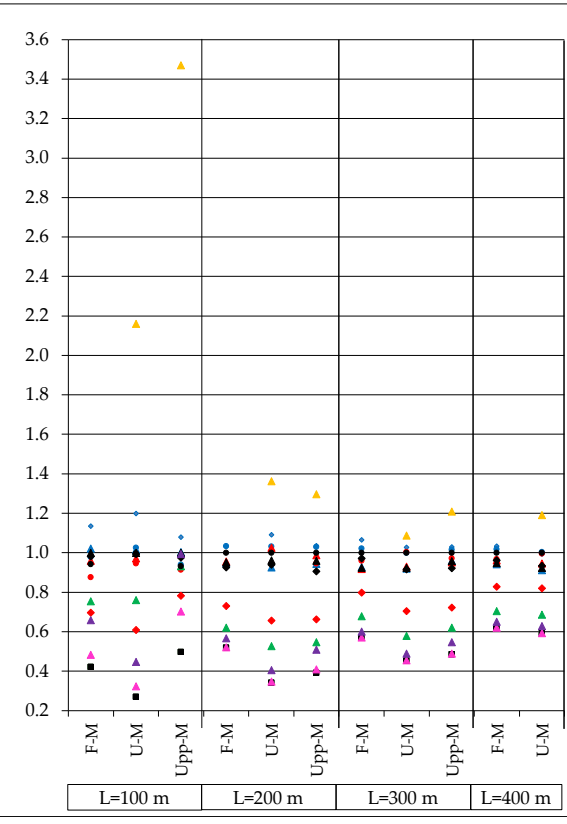

(b)
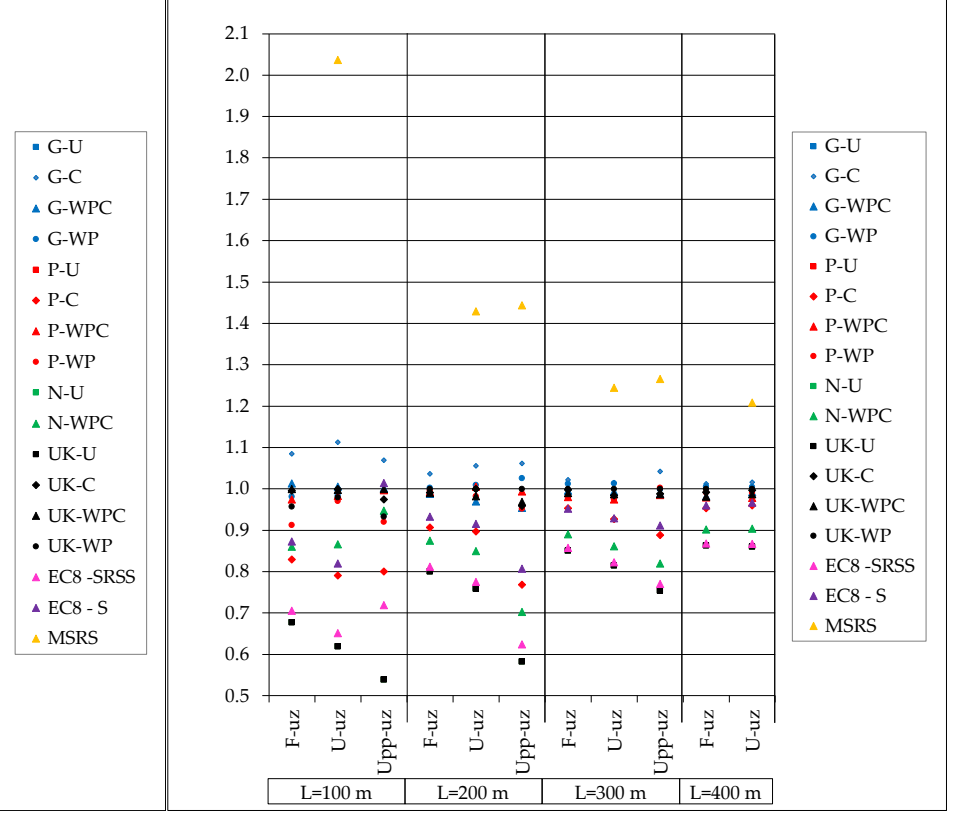

(c)

Figure 13. Ratios $\rho_{2}$ at arch crown for: (a) axial forces; (b) bending moments; (c) vertical displacements *. ${ }^{*}$ note: for clarity of the figure (c), the large $\rho_{2}$ of the bridge Upp100 amounting to 3.65 obtained using the MSRS method was disregarded 
Results show that simplified procedure proposed by EC8 generally underestimates the response of analyzed arch bridges to MSE, regardless of span. At quarter span, the ratios $\rho_{2}$ of the internal forces are in the range of 0.67 (0.72 for EC8-S) to 0.94 for EC8-SRSS (1.28 for EC8-S) for the bending moment of the bridge Upp100. The vertical displacements are in relatively good agreement with the reference values (in the range of 0.82 to 0.94 for EC8-SRSS and 0.97 to 1.14 for EC8-S). At the arch crown, the values obtained by both EC8 cases are far below the reference values, with the lowest ratio amounting to 0.32 occurring for bending moments in the bridge U100. Vertical displacements are in the range of 0.62 to 0.87 for EC8-SRSS and 0.81 to 1.01 for EC8-S for all bridges. Results are not presented for the arch springing as they follow the same trend as those commented above.

Regarding the records used in the time-history method, it may be observed that all values obtained using records from NYCDOT are significantly lower than all other values, which has been expected as the elastic response spectrum prescribed by NYCDOT is more favorable for analyzed bridges than that of EC8. The most detrimental values are calculated using the record generated using unconditional simulation, what has also been anticipated accounting for the characteristics of the signal, which cannot be considered realistic.

The MSRS method mostly gives conservative values for MSE. At quarter span, the values of the internal forces are in relatively good agreement (up to 1.16), except for the bridge Upp100 where the ratio for axial force amounts to 1.49 and 3.73 for the bending moment. Vertical displacements are significantly overestimated for stiff bridges, especially for the bridge Upp100 where the ratio amounts to 5.4. At arch crown, the values obtained by MSRS are very different than the reference values, ranging from 0.5 to 3.65 .

It is interesting to compare the pseudo-static and dynamic component of the response, in MSRS method, for two bridges of the same span but different stiffness, U100 and Upp 100 (Figure 14a,b). It may be observed that for the displacement of the bridge U100 the pseudo-static component prevails, while the dynamic one is more important for the internal forces. For very stiff bridge Upp100, pseudo-static component is more important for all response values and it is the main reason for very unfavorable response of this bridge to MSE. These components are also presented for a flexible bridge U400, where the dynamic component dominantly affects all the response values (Figure 14c). It is repeated herein that the dynamic component of the response to MSE differs from the one to uniform excitation. These conclusions are in line with those obtained by Hao [23], who investigated circular arches and concluded that the responses of stiff arches are generally dominated by the quasi-static responses, while the dynamic responses dominate the flexible arch responses owing to a dynamic amplification effect.

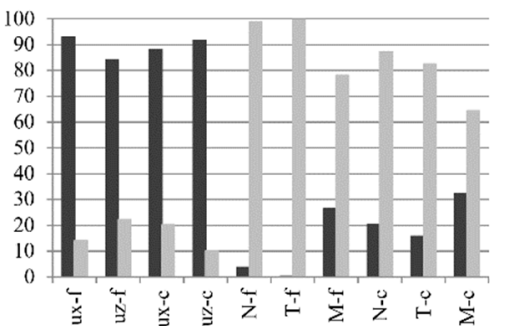

(a)

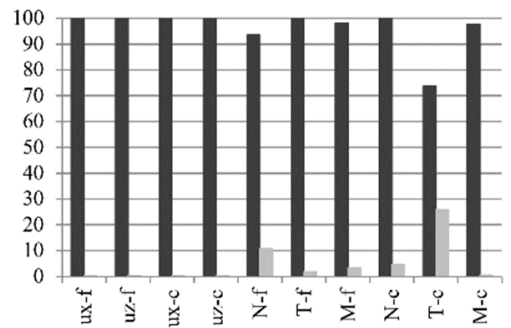

(b)

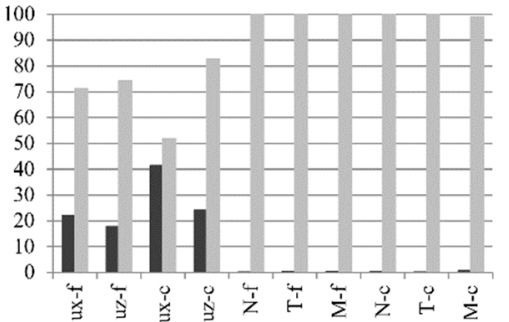

(c)

Figure 14. Pseudo-static (in black color) and dynamic (in grey color) part of the response: (a) bridge Upp100; (b) bridge U100; (c) bridge U400.

\section{Discussion}

\subsection{Influence of Structural Dynamic Parameters and Span Length}

The influence of dynamic properties of the system on response values cannot be observed, except for the vertical displacements of the arch crown where it is evident that within one group of 
arch spans (for example, $\mathrm{L}=100 \mathrm{~m}$ ) the unfavorable action of the MSE increases with the stiffness of the system.

The detrimental effect of the MSE on the values of the bending moments and the longitudinal displacements of the quarter arch generally increases with the increase of the span within the same static system. For all crown displacements, the opposite is true, so that increasing the span results in decreasing the unfavorable effect of MSE.

\subsection{Influence of MSE Effects}

Analyzing ratios $\rho_{1}$ it may be observed that the wave-passage effect is in most cases more detrimental to the response than the loss of coherency. Exceptions occur for bridges F100 and Upp100. However, it should be noted that when values obtained by calculation using records generated by unconditional and conditional simulation are analyzed separately, in many cases the most unfavorable form of MSE is that with the effect of coherence loss using records obtained by unconditional simulation calculations, while for the values obtained from calculations using records generated by conditional simulation, in most cases the most unfavorable form of MSE is the one with the influence of the wave-passage.

Hence, the general trend of the behavior of the observed values cannot be determined and the results depend on the records used. Therefore, it is recommended that the design analyses should include both considered MSE effects.

\subsection{Influence of Analysis Methods and Applied Ground-Motion Time-Histories}

As previously mentioned, the largest average peak time-history results obtained using generated records were assumed as the reference values for validation of all methods.

The simplified method proposed in EC8 systematically underestimates response values and, therefore, it is not suggested for the analysis of similar bridges. This conclusion is in accordance with the findings of some other studies in which EC8 simplified method was applied. For example, in the recent study of the integral bridge [22], it was concluded that EC 8 approach provides results in the order of $\pm 40-50 \%$ of the reference values, owing to the inability of the method to predict the contribution of higher modes as well as the location of structural elements which are favorably or unfavorably affected by spatially variable seismic actions. The research presented in [18] dealt with the response of bridges to MSE and evaluation of EC8 provisions very comprehensively. The authors concluded that in some cases the provisions of the EC8 on the simplified method may be safely applied, but in other cases ignoring the effect of MSE or performing simplified calculations can significantly underestimate the actual seismic demand. In the study of an arch bridge response to multiple-support excitation presented in [33] the authors also suggested reexamining the limit for consideration of spatial variability effect in concrete arch bridges, proposed by Eurocode 8 .

Moreover, the modification of the method in which the combination of the most adverse dynamic response with the most adverse effects obtained by the quasi-static analyses is calculated by applying the sum of absolute values, applied also in [18], cannot be recommended for the use since the response values are still underestimated, with a few exceptions that cannot influence the method selection.

It can be observed that the response spectrum method MSRS does not accurately estimate the response of arch bridges to MSE, with some values being significantly lower and some higher than the reference values, which is in line with the research presented in [62], proposing its modification. Therefore, bearing in mind also the general inapplicability of the method to any non-linear analysis, this method is not recommended for the calculation of similar bridges to MSE.

The use of earthquake records generated by unconditional simulation produces very conservative results, and it should be kept in mind that such "artificial" records are used because of the lack of recorded ones and they can never realistically define an earthquake excitation. The advantage of using such a simulation is that it simply and quickly generates a large number of records once a calculation algorithm is made, which is useful for parametric analyses. The procedure of conditional simulation 
using recorded motions is more demanding, because it is firstly necessary to find a series of appropriate records from a strong-motion database with respect to the bridge location (which is not always possible), taking into account the code rules and, if necessary, to process them (baseline correction and filtering). Then, for each selected record, the time windows and the spectral power density function for each of these should be determined, taking care that the duration of each stationary time window is $2 n$ since inverse fast Fourier transforms are used in the simulation. It is evident that it is very challenging to fully automatize such a process. Only after this initial selection and adjustment procedure has been carried out can the process of generating records for the other supports of the bridge be initiated. The records generated using this method retain the properties of the original recorded time-histories (for example, the frequency content of the signal) so that they can more realistically define the earthquake excitation than the "artificial" records generated on the basis of a probabilistic model. Taking into account these findings, it is suggested that, depending on the problem itself (for example, design or theoretical parameter analyses), a record generation process should be selected. It is further noted that special attention should be paid to the processing of acceleration records, since displacement records are generally used in the analysis of the MSE effect.

\section{Conclusions}

This study investigated the influence of multiple-support excitation on seismic behavior of deck-type long-span reinforced concrete arch bridges. Results of the comprehensive analysis showed that applying a uniform seismic input at all bridge supports, as is commonly done in engineering practice, was not acceptable for these bridges. In all studied cases, multiple-support excitation had a detrimental effect on some aspect of the arch bridge seismic response, regardless of span length (the minimal span was $100 \mathrm{~m}$ ). Hence, it may be recommended that this phenomenon is included in seismic analysis of similar structures, even if it is not required by the engineering design codes.

Both ground-motion effects acting separately or simultaneously proved to be very important, with their relative significance depending on response values, analyzed arch locations, and utilized earthquake time histories. Therefore, it is suggested that both MSE effects are considered in seismic analysis of similar bridges. It should be pointed out that deck arch bridges of long spans are usually constructed on rock sites, because of the large arch thrust that needs to be transferred to the ground. Therefore, the effect of local-site conditions was not considered in addition to coherency loss and wave-passage. However, if the bridge location is at uneven site with non-uniform conditions at different supports, this influence on ground motion amplification and spatial variation should be considered. A simplified approach would be to apply the procedure presented in this paper (Figure 6), but to define different response spectra taking into account the soil category of different supports. However, one should bear in mind that the local site conditions have a much more complex effect than the spectral modification prescribed by the code design spectra and thus, a more comprehensive approach to this effect may be suggested, such as that applied in e.g., $[18,63]$. Moreover, if the foundation interacts with the soil and the superstructure, thus significantly affecting the dynamic response of the bridge, this further complicates the analysis, and the state-of-the-art knowledge in geotechnical earthquake engineering and earthquake structural engineering should be applied accordingly. The soil-structure interaction may reduce the effect of multiple-support excitation by increasing the fundamental period of the structure and by introducing the dissipation of energy at foundations level. However, foundation rotations may induce large pseudo-static forces [64]. It was concluded in [18] that significant coupling exists between spatial variability, effects of local soil conditions and SSI effects, but their relative importance cannot be easily assessed in advance.

In this research, no rule in response of bridges was apparent regarding the effect of dynamic structural properties and arch span, with few exceptions. Comparison of the various methods showed that the most suitable analysis procedure was time-history method, because other procedures proved to be less accurate and because of its general applicability. In particular, it was shown that simplified method proposed by valid European seismic codes systematically underestimates the MSE effect, 
so it is not recommended for use in engineering practice. EC8 rules, which specify that in the case of roughly uniform soil properties along the bridge, spatial variability must only be considered if the bridge length is larger than $400 \mathrm{~m}$ for rocky soils, cannot be safely used to analyze deck-reinforced concrete arch bridges. The other code deficiencies were also observed, such as the lack of guidelines on selecting the coherency loss functions and apparent wave velocities. These findings are corroborated by a recent paper [64] addressing these issues and, furthermore, by proposals of simplified differential displacement loading patterns for use in the seismic design of bridges accounting for MSE by the same authors [65], and we believe that the new generation of EC seismic standards should consider these studies.

Although presented conclusions have been drawn from a limited-scope study of plane response of deck-type reinforced concrete arch bridges founded on rock sites, it is obvious that many gaps still exist in successful inclusion of MSE effect into the design standards and in providing guidelines that could be useful and understandable to engineering professionals. Therefore, it may be suggested to undertake more initiatives to investigate the effect of MSE on bridges of various types and materials, soil conditions and earthquake scenarios, using numerical procedures, but also experimental research, as superior systems of multiple shaking tables have been installed in several research institutions worldwide.

Author Contributions: D.L. initiated and supervised this study. M.S.N. performed the core research (all numerical examples) and wrote the initial draft of the paper. J.A. and M.U. checked the results of the study, helped in data processing and revised the paper. All authors have read and agreed to the published version of the manuscript.

Funding: This research was partially funded by Ministry of Science, Education and Sports of Republic of Croatia, under study Non-standard models of building structures, grant number 082-1201829-2166.

Acknowledgments: The authors would like to thank Department of Geophysics, Faculty of Science, University of Zagreb, for providing ground motions recorded on the Adriatic Coast and to colleagues from the Department of Structures, Faculty of Civil Engineering, University of Zagreb, who designed some of the bridges used for creating prototypes and supplied all bridge data necessary for the analyses.

Conflicts of Interest: The authors declare no conflict of interest.

\section{References}

1. Gazetas, G.; Simeonov, V.; Reinhorn, A.M.; Buckle, I.G. Implications of Spatial Variation of Ground Motion on the Collapse of Sr14/I5 Southbound Separation and Overhead Bridge in the Northridge Earthquake. ACI Int. 1999, 187, 299-327.

2. Tzanetos, N.; Elnashai, A.S.; Hamdan, F.H.; Antoniou, S. Inelastic Dynamic Response of RC Bridges Subjected to Spatial Non-Synchronous Earthquake Motion. Adv. Struct. Eng. 2000, 3, 191-214. [CrossRef]

3. Yashinsky, M. Bridge Repairs After the 1995 Kobe (Hyogo-ken Nanbu) Earthquake. In Lessons Learned Over Time-Learning From Earthquake Series, Volume III; Earthquake Engineering Research Institute: Oakland, CA, USA, 2000.

4. Earthquake Engineering Research Center. Seismological and Engineering Aspects of the 1995 Hyogoken-Nanbu (Kobe) Earthquake, Report No. UCB/EERC 95-10; Earthquake Engineering Research Center, College of Engineering, University of California: Berkeley, CA, USA, 1995.

5. Bogdanoff, J.L.; Goldberg, J.E.; Schiff, A.J. The effect of ground transmission time on the response of long structures. Bull. Seismol. Soc. Am. 1965, 55, 627-640.

6. Bolt, B.A.; Loh, C.H.; Penzien, J.; Tsai, Y.B.; Yeh, Y.T. Preliminary Report on the SMART 1 Strong Motion Array in Taiwan, Report No. UCB/EERC-82/13; Earthquake Engineering Research Center, College of Engineering, University of California: Berkeley, CA, USA, 1982.

7. Zerva, A. Spatial Variation of Seismic Ground Motions: Modeling and Engineering Applications; CRC Press: Boca Raton, FL, USA, 2009.

8. Zerva, A.; Zervas, V. Spatial variation of seismic ground motions: An overview. Appl. Mech. Rev. 2002, 55, 271. [CrossRef]

9. Harichandran, R.S. Spatial Variation of Earthquake Ground Motion, What is it, How do We Model it, and What are Its Engineering Implications; Michigan State University: East Lansing, MI, USA, 1999.

10. Kramer, S.L. Geotechnical Earthquake Engineering; Prentice Hall: Upper Saddle River, NJ, USA, 1996. 
11. Reiter, L. Earthquake Hazard Analysis: Issues and Insights; Columbia University Press: New York, NY, USA, 1990.

12. Savor Novak, M.; Lazarević, D.; Atalić, J. Influence of spatial variability of ground motion on seismic response of bridges. Gradevinar 2015, 67, 943-957.

13. Monti, G.; Nuti, C.; Pinto, P.E. Nonlinear response of bridges under multi support excitation. J. Struct. Eng. ASCE 1996, 122, 1147-1159. [CrossRef]

14. Lupoi, A.; Franchin, P.; Pinto, P.E.; Monti, G. Seismic design of bridges accounting for spatial variability of ground motion. Earthq. Eng. Struct. Dyn. 2005, 34, 327-348. [CrossRef]

15. Shinozuka, M.; Saxena, V.; Deodatis, G. Effect of Spatial Variation of Ground Motion on Highway Structures, Technical Report MCEER 00 0013; Multidisciplinary Center for Earthquake Engineering Research (MCEER), University at Buffalo, State University of New York: Buffalo, NY, USA, 2000.

16. Burdette, N.J.; Elnashai, A.S.; Lupoi, A.; Sextos, A.G. The Effect of Asynchronous Earthquake Motion on Complex Bridges; Mid-America Earthquake Center, Department of Civil Engineering at the University of Illinois at Urbana-Champaign: Urbana, IL, USA, 2006; pp. 1-28.

17. Sextos, A.G.; Kappos, A.J. Evaluation of seismic response of bridges under asynchronous excitation and comparisons with Eurocode 8-2 provisions. Bull. Earthq. Eng. 2009, 7, 519-545. [CrossRef]

18. Sextos, A.G.; Kappos, A.J.; Pitilakis, K.D. Inelastic dynamic analysis of RC bridges accounting for spatial variability of ground motion, site effects and soil-structure interaction phenomena. Part 2: Parametric study. Earthq. Eng. Struct. Dyn. 2003, 32, 629-652. [CrossRef]

19. Sextos, A.; Karakostas, C.; Lekidis, V.; Papadopoulos, S. Multiple support seismic excitation of the Evripos bridge based on free-field and on-structure recordings. Struct. Infrastruct. Eng. 2015, 11, 1510-1523. [CrossRef]

20. Dumanogluid, A.A.; Soyluk, K. A stochastic analysis of long span structures subjected to spatially varying ground motions including the site-response effect. Eng. Struct. 2003, 25, 1301-1310. [CrossRef]

21. Adanur, S.; Altunişik, A.C.; Soyluk, K.; Bayraktar, A.; Dumanoğlu, A.A. Multiple-support seismic response of Bosporus Suspension Bridge for various random vibration methods. Case Stud. Struct. Eng. 2016, 5, 54-67. [CrossRef]

22. Özcebe, A.G.; Smerzini, C.; Bhanu, V. Insights into the Effect of Spatial Variability of Recorded Earthquake Ground Motion on the Response of a Bridge Structure. J. Earthq. Eng. 2018, 1-27. [CrossRef]

23. Hao, H. Ground-Motion Spatial Variation Effects on Circular Arch Responses. J. Eng. Mech. ASCE 1994, 120, 2326-2341. [CrossRef]

24. Huang, C.S.; Teng, T.J.; Yeh, C.H.; Chi, C.H. Transient Response of Circular Arches for Base Excited Motions. In Proceedings of the 11th World Conference on Earthquake Engineering, Acapulco, Mexico, 23-28 June 1996; Pergamon: Oxford, UK, 1996; p. 240.

25. Su, L.; Dong, S.; Kato, S. Seismic design for steel trussed arch to multi-support excitations. J. Constr. Steel ReS. 2007, 63, 725-734. [CrossRef]

26. Harichandran, R.S.; Hawwari, A.; Sweidan, B.N. Response of Long-span Bridges to Spatially Varying Ground Motion. J. Struct. Eng. 1996, 122, 476-484. [CrossRef]

27. Soyluk, K. Comparison of random vibration methods for multi-support seismic excitation analysis of long-span bridges. Eng. Struct. 2004, 26, 1573-1583. [CrossRef]

28. Dusseau, R.A.; Wen, R.K. Seismic Response of Deck-type Arch Bridges. Earthq. Eng. Struct. Dyn. 1989, 18, 701-715. [CrossRef]

29. Kawashima, K.; Mizoguti, A. Seismic Response of a Reinforced Concrete Arch Bridge. In Proceedings of the 12th World Conference on Earthquake Engineering, Auckland, New Zealand, 30 January-4 February 2000; New Zealand Society for Earthquake Engineering: Upper Hutt, New Zealand, 2000; p. 1824.

30. Zanardo, G.; Pellegrino, C.; Bobisut, C.; Modena, C. Performance Evaluation of Short Span Reinforced Concrete Arch Bridges. J. Bridg. Eng. ASCE 2004, 9, 424-434. [CrossRef]

31. Savor, M.; Lazarevic, D.; Atalic, J. Influence of spatial variability of ground motion on response of large concrete arch bridges. In Proceedings of the IABSE-IASS Symposium, London, UK, 20-23 September 2011; Hemming Group Limited: London, UK, 2011; p. 160.

32. McCallen, D.; Noble, C.; Hoehler, M. The Seismic Response of Concrete Arch Bridges with Focus on the Bixby Creek Bridge, California, UCRL_ID—134419; Lawrence Livermore National Laboratory for California Department of Transportation: Livermore, CA, USA, 1999. 
33. Álvarez, J.J.; Aparicio, A.C.; Jara, J.M.; Jara, M. Seismic assessment of a long-span arch bridge considering the variation in axial forces induced by earthquakes. Eng. Struct. 2012, 34, 69-80. [CrossRef]

34. Papadopoulos, S.P.; Sextos, A.G. On the Excitation of Higher Modes of Long Bridges Due to Spatial Variability of Earthquake Ground Motion; Innov. Bridg. Soil-Bridge Interact. (IBSBI): Athens, Greece, 2011.

35. Savor, Z. New Contribution to Development of Arch Bridges. Ph.D. Thesis, Faculty of Civil Engineering, University of Zagreb, Zagreb, Croatia, 2005.

36. CEN. Eurocode 8: Design of Structures for Earthquake Resistance-Part 1: General Rules, Seismic Actions and Rules for Buildings; CEN European Committee for Standardisation: Brussels, Belgium, 2004.

37. CEN. Eurocode 2: Design of Concrete Structures-Part 1-1: General Rules and Rules for Buildings; CEN European Committee for Standardisation: Brussels, Belgium, 2004.

38. Wilson, E.L. Three-Dimensional Static and Dynamic Analysis of Structures A Physical Approach with Emphasis on Earthquake Engineering; Computers and Structures, Inc.: Berkeley, CA, USA, 2002.

39. Priestley, M.J.N.; Seible, F.; Calvi, G.M. Seismic Design and Retrofit of Bridges; John Wiley \& Sons: New York, NY, USA, 1996.

40. CSI. CSI Analysis Reference Manual for SAP2000, SAFE and CSiBridge; Computers \& Structures: Berkeley, CA, USA, 2010.

41. Mathematica; Version 10.0; Wolfram Research, Inc.: Champaign, IL, USA, 2010.

42. Seismostruct; Version 6; Seismosoft Ltd.: Pavia, Italy, 2012.

43. Loh, C.H.; Lin, S.G. Directionality and simulation in spatial variation of seismic waves. Eng. Struct. 1990, 12, 134-143. [CrossRef]

44. Hao, H.; Oliveira, C.S.; Penzien, J. Multiple-station ground motion processing and simulation based on smart-1 array data. Nucl. Eng. Des. 1989, 111, 293-310. [CrossRef]

45. Abrahamson, N.A.; Schneider, J.F.; Stepp, J.C. Spatial variation of strong ground motion for use in soil-structure interaction analyses. In Proceedings of the 4th US-National Conference on Earthquake Engineering, Palm Springs, CA, USA, 20-24 May 1990; pp. 317-326.

46. Harichandran, R.S.; Vanmarcke, E.H. Stochastic variation of earthquake ground motion in space and time. J. Eng. Mech. 1986, 112, 154-174. [CrossRef]

47. Somerville, P.G.; McLaren, J.P.; Saikia, C.K.; Helmberger, D.V. Site-specific estimation of spatial incoherence of strong ground motion. In Earthquake Engineering and Soil Dynamics II-Recent Advances in Ground Motion Evaluation; Von Thun, J.L., Ed.; ASCE: New York, NY, USA, 1988.

48. Der Kiureghian, A. A coherency model for spatially varying ground motions. Earthq. Eng. Struct. Dyn. 1996, 25, 99-111. [CrossRef]

49. Luco, J.E.; Wong, H.L. Response of a rigid foundation to a spatially random ground motion. Earthq. Eng. Struct. Dyn. 1986, 14, 891-908. [CrossRef]

50. Abrahamson, N.A. Hard Rock Coherency Functions Based on the Pinyon Flat Array Data; Electric Power Research Institute: Palo Alto, CA, USA, 2007.

51. Abrahamson, N.A. Spatial Variation of Multiple Support Inputs. In Proceedings of the First U.S. Seminar, Seismic Evaluation and Retrofit of Steel Bridges, Berkeley, CA, USA, 18 October 1993.

52. Tajimi, H. A Statistical Method of Determining the Maximum Response of a Building Structure during an Earthquake. In Proceedings of the 2nd World Conference on Earthquake Engineering, Tokyo and Kyoto, Japan, 11-18 July 1960; pp. 781-797.

53. Clough, R.W.; Penzien, J. Dynamics of Structures, 2nd ed.; McGraw-Hill, Inc.: New York, NY, USA, 1993.

54. Kaul, M.K. Stochastic characterization of earthquakes through their response spectrum. Earthq. Eng. Struct. Dyn. 1978, 6, 497-509. [CrossRef]

55. Der Kiureghan, A.; Neuenhofer, A. Response spectrum method for multi-support excitations. Earthq. Eng. Struct. Dyn. 1992, 21, 713-740. [CrossRef]

56. Der Kiureghian, A.; Keshishian, P.; Halabian, A.M. Multiple Support Response Spectrum Analysis of Bridges Including the Site-Response Effect \& the MSRS Code 1997, Report No. UCB/EERC-97/02; Earthquake Engineering Research Center, College of Engineering, University of California: Berkeley, CA, USA, 1997.

57. CEN. Eurocode 8: Design of Structures for Earthquake Resistance-Part 2: Bridges; CEN European Committee for Standardisation: Brussels, Belgium, 2005.

58. Deodatis, G. Non-stationary stochastic vector processes: Seismic ground motion applications. Probabilistic Eng. Mech. 1996, 11, 149-167. [CrossRef] 
59. Vanmarcke, E.H.; Heredia-Zavoni, E.; Fenton, G.A. Conditional Simulation of Spatially Correlated Earthquake Ground Motion. J. Eng. Mech. ASCE 1993, 119, 2333-2352. [CrossRef]

60. Vanmarcke, E.H.; Fenton, G.A.; Heredia-Zavoni, E. SIMQKE-II, Conditioned Earthquake Ground Motion Simulator, User's Manual 2.1; Princeton University: Princeton, NJ, USA, 1999.

61. New York City Department of Transportation. Multiple Support Motions Time-Histories; NYC DOT: New York, NY, USA, 2004.

62. Shen, J.; Li, R.; Shi, J.; Zhou, G. Modified multi-support response spectrum analysis of structures with multiple supports under incoherent ground excitation. Appl. Sci. 2019, 9, 1744. [CrossRef]

63. Bi, K.; Hao, H. Modelling and simulation of spatially varying earthquake ground motions at sites with varying conditions. Probabilistic Eng. Mech. 2012, 29, 92-104. [CrossRef]

64. Falamarz-Sheikhabadi, M.R.; Zerva, A. Two uncertainties in simulating spatially varying seismic ground motions: Incoherency coefficient and apparent propagation velocity. Bull. Earthq. Eng. 2018, 16, 4427-4441. [CrossRef]

65. Falamarz-Sheikhabadi, M.R.; Zerva, A. Simplified displacement loading patterns for incorporation of spatially variable ground motions in bridge seismic design codes. J. Bridge Eng. 2017, 22, 04017010-1-04017010-14. [CrossRef]

(C) 2019 by the authors. Licensee MDPI, Basel, Switzerland. This article is an open access article distributed under the terms and conditions of the Creative Commons Attribution (CC BY) license (http://creativecommons.org/licenses/by/4.0/). 